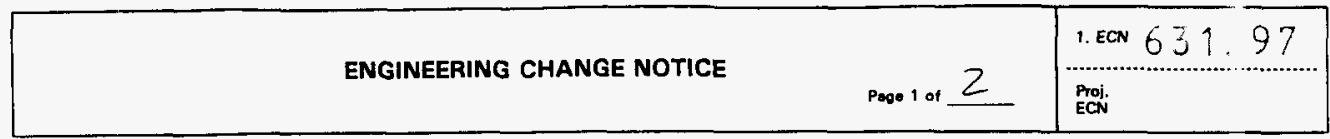

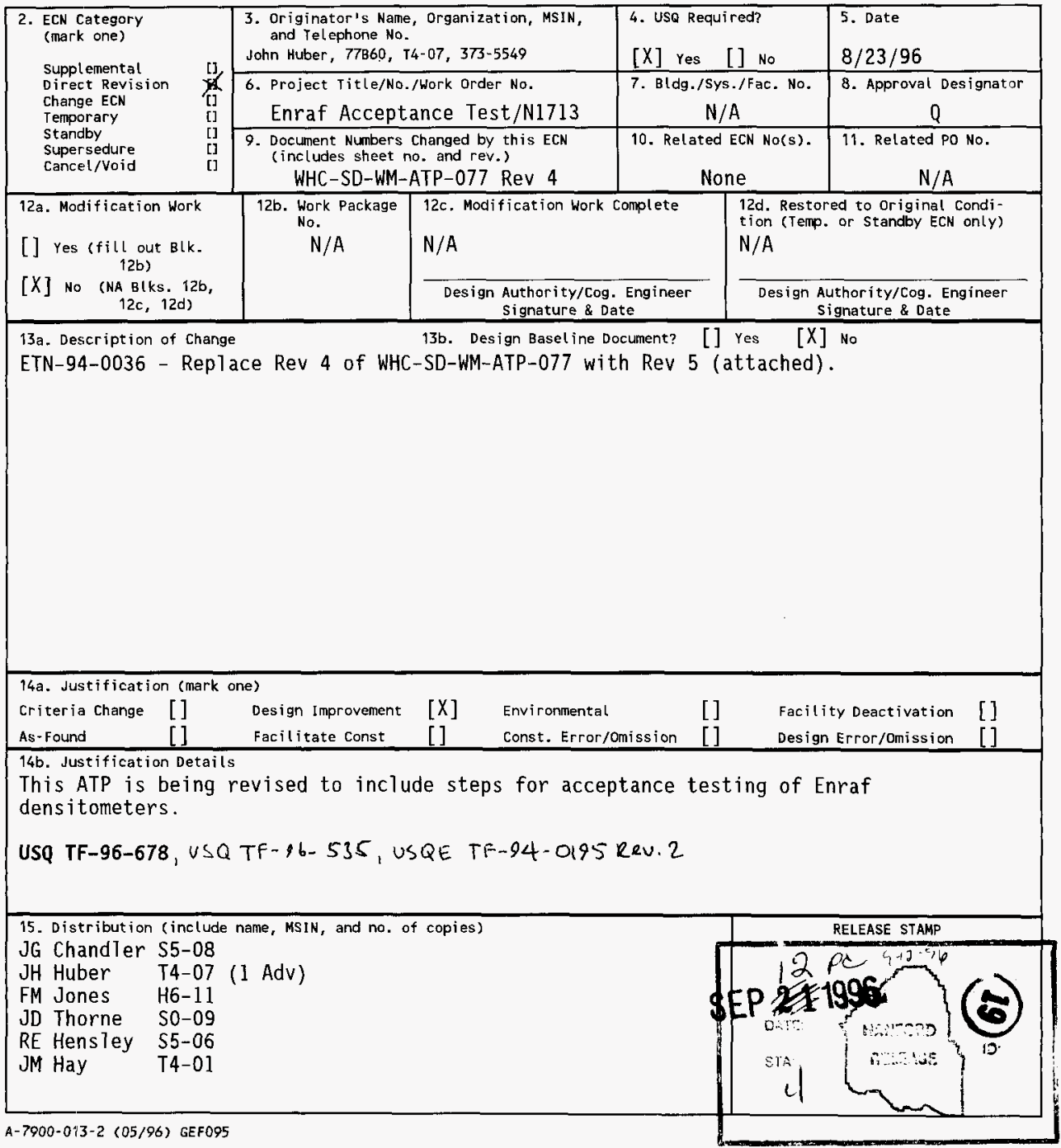




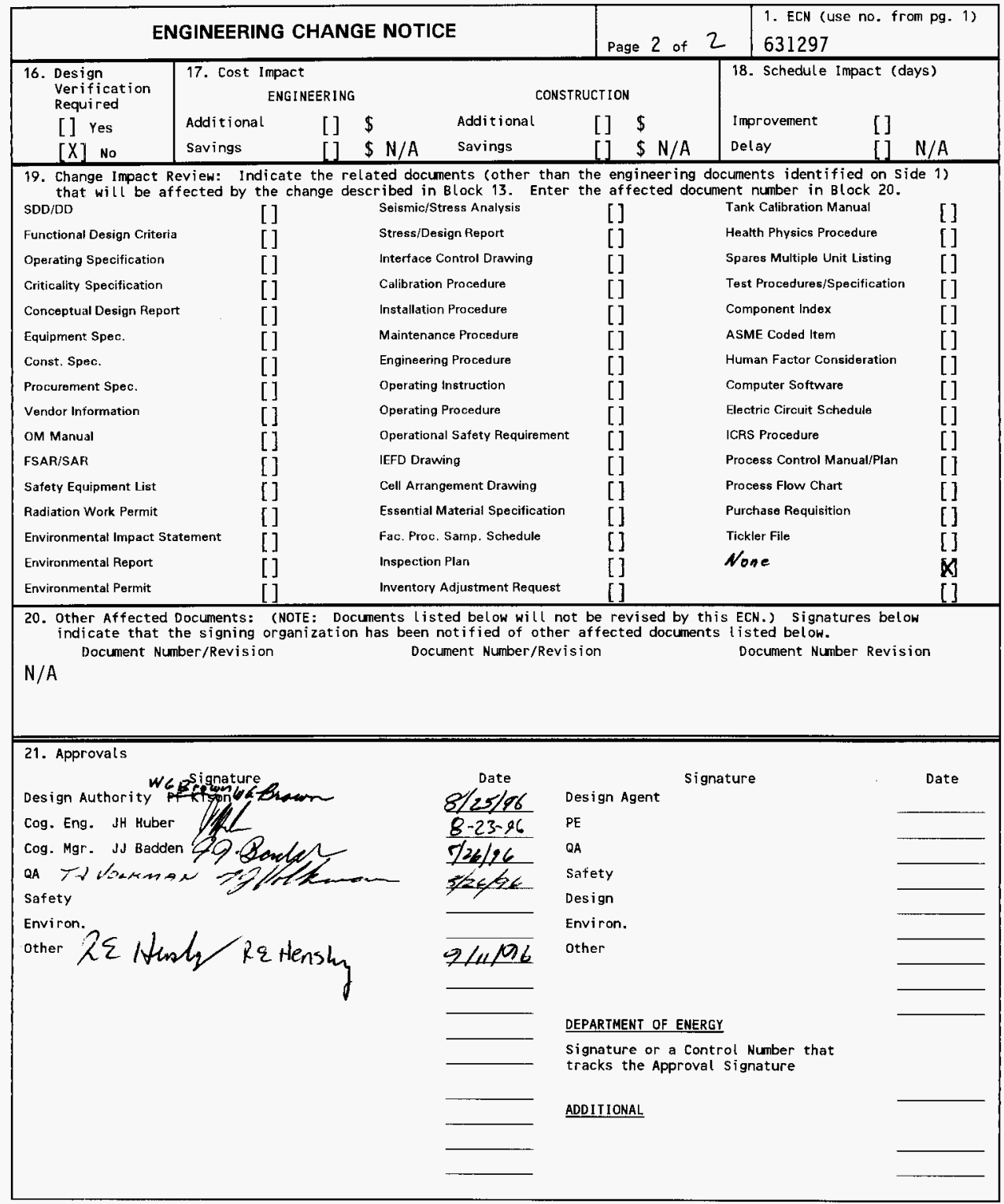




\title{
Enraf Series 854 Advanced Technology Gauge (ATG) Acceptance Test Procedure
}

\author{
John Huber \\ Westinghouse Hanford Company, Richland, WA 99352 \\ U.S. Department of Energy Contract DE-AC06-87RL10930 \\ EDT/ECN: ECN 631297 UC: \\ Org Code: 77B60 Charge Code: N1638 \\ B\&R Code: Total Pages: 28
}

Key Words: Enraf, ATG Series 854, Level Gauge, LIT, Level Indicating Transmitter

Abstract: This Acceptance Test Procedure was written to test the Enraf Series 854 ATG prior to installation in the Tank Farms. The procedure sets various parameters and verifies that the gauge is functional.

TRADEMARK DISCLAIMER. Reference herein to any specific commercial product, process, or service by trade name, trademark, manufacturer, or otherwise, does not necessarily constitute or imply its endorsement, recommendation, or favoring by the United States Government or any agency thereof or its contractors or subcontractors.

Printed in the United States of America. To obtain copies of this document, contact: WHC/BCS Document Control Services, P.0. Box 1970, Mailstop H6-08, Richland WA 99352, Phone (509) 372-2420; Fax (509) 376-4989.
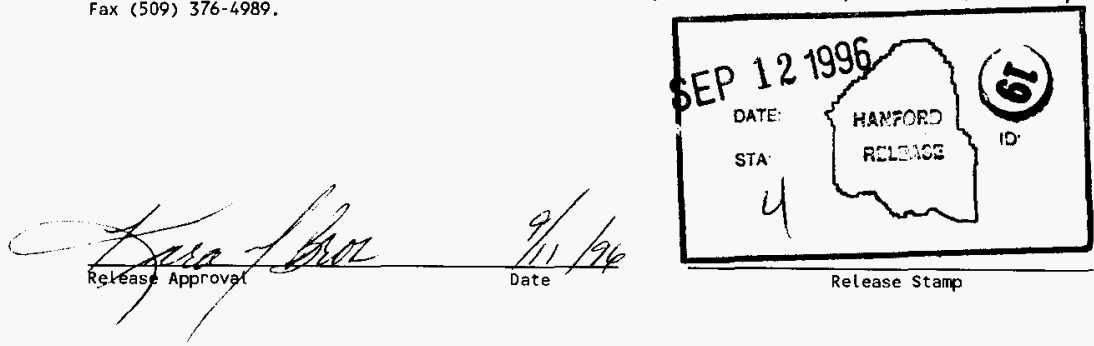

Approved for Public Release 


\section{RECORD OF REVISION}

(2) Title

ENRAF SERIES 854 ADVANCED TECHNOLOGY GAUGE (ATG) ACCEPTANCE TEST PROCEDURE

CHANGE CONIROL RECORD

\begin{tabular}{|c|c|c|c|}
\hline \multirow{2}{*}{ (3) Revision } & \multirow{2}{*}{ (4) Description of Change - Replace, Add, and Delete Pages } & \multicolumn{2}{|c|}{ Authorized for Release } \\
\hline & & (5) Cog. Engr. & (6) Cog. Mgr. \\
\hline 0 & (7) EDT $141624,2 / 18 / 94$ & GA Barnes & TL Moore \\
\hline $0-A$ & $\begin{array}{l}\text { Add Record of Revision page } i \\
\text { Replaces pages } 2 \text { of } 14 \text { and } 14 \text { of } 14 . \\
\text { ECN } 602579,4 / 15 / 94\end{array}$ & & \\
\hline $0-B$ & $\begin{array}{l}\text { Replaces Record of Revision page } i \\
\text { Replaces pages } 10 \text { of } 14 \text { and } 14 \text { of } 14 \\
\text { ECN } 602580,5 / 3 / 94\end{array}$ & & \\
\hline $0-C$ & $\begin{array}{l}\text { Replace Record of Revision page } i \\
\text { Replaces pages } 4,6,9,12 \text {, and } 14 \\
\text { Add Appendix A } \\
\text { ECN } 608122,5 / 24 / 94\end{array}$ & & \\
\hline 1 & $\begin{array}{c}\text { Replace Rev 0-C with Rev 1 } \\
{ }^{\star} \text { ECN } 608123, \text { ECN 613180, } \\
7 / 20 / 94\end{array}$ & & \\
\hline 2 & $\begin{array}{l}\text { Replace Rev } 1 \text { with Rev } 2 \\
\text { Rev } 2 \text { is a complete rewrite } \\
\text { ECN } 613319,1 / 24 / 95\end{array}$ & & \\
\hline 3 & $\begin{array}{l}\text { Replace Rev } 2 \text { with Rev } 3 \\
\text { Rev } 3 \text { is a complete rewrite } \\
\text { ECN } 620620,5 / 5 / 95 \\
\end{array}$ & & \\
\hline 4 & $\begin{array}{l}\text { Replace Rev } 3 \text { with Rev } 4 \\
\text { Rev } 4 \text { is an update } \\
\text { ECN } 631224,3 / 27 / 96\end{array}$ & & \\
\hline BS. & $\begin{array}{c}\text { Replace Rev } 4 \text { with Rev } 5 \\
\text { Rev } 5 \text { incorporates testing requirements for } \\
\text { Enraf Densitometers. } \\
\text { ECN } 631297 \\
\end{array}$ & $\int_{8-26.96}$ & $8 / 26 / 96$ \\
\hline & & & \\
\hline & & & \\
\hline & & & \\
\hline & & & \\
\hline & & & \\
\hline & & & \\
\hline & & & \\
\hline & & & \\
\hline & & & \\
\hline & & & \\
\hline & & & \\
\hline
\end{tabular}


WHC-SD-WM-ATP-077

REV 5

ENRAF SERIES 854 ADVANCED TECHNOLOGY GAUGE (ATG) ACCEPTANCE TEST PROCEDURE

\author{
J. H. Huber \\ Tank Farm Transition Projects Engineering
}

August 22, 1996 
1.0 INSTRUCTIONS . . . . . . . . . . . . . . . . . 2

1.1 PURPOSE . . . . . . . . . . . . . . . . . 2

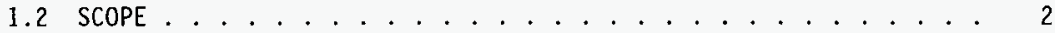

1.3 REFERENCES .................... . . . . 2

1.4 RESPONSIBILITIES . . . . . . . . . . . . . . . . 2

1.5 DESCRIPTION OF THE SYSTEM . . . . . . . . . . . . . . . . . . . 3

1.6 TEST CONDITIONS AND EQUIPMENT REQUIRED . . . . . . . . . 3

2.0 TEST EXECUTION SECTION . . . . . . . . . . . . . . . . . . . . . . 4

2.1 INITIALIZING THE GAUGE ................... . . . 5

2.2 CHECKING FOR ERROR CODES ............... . . 5

2.3 TESTING THE LEVEL GAUGE OPERABILITY . . . . . . . . . . 6

2.6 TESTING THE DISPLAY (Densitometers On1y) ........... 10

2.7 DENSITY CALIBRATION SETUP (Densitometers Only) . . . . . . 11

2.8 DENSITY CALIBRATION (Densitometers Only) . . . . . . . . . . . 11

2.9 TRANSPORTING THE LEVEL GAUGE . . . . . . . . . . . . 15

3.0 EXCEPTIONS TO ACCEPTANCE TEST . . . . . . . . . . . . . . . 16

4.0 TEST DATA MANAGEMENT . . . . . . . . . . . . . . . . . 16

4.1 ACCEPTANCE TEST REPORT GUIDANCE . . . . . . . . . . . . . . . . 16

TEST EXECUTION DATA SHEET . . . . . . . . . . . . . . . . 17

EXCEPTIONS DATA SHEET . . . . . . . . . . . . . . . . . 19

APPENDIX A . . . . . . . . . . . . . . . . . . . . A A-1

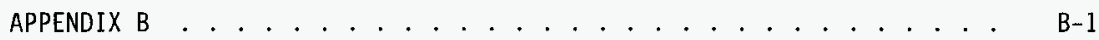

APPENDIX $\mathrm{C} \ldots \ldots \ldots \ldots$ C $\mathrm{C}-1$ 
WHC-SD-WM-ATP-077

REV 5

\section{ENRAF SERIES 854 ADVANCED TECHNOLOGY GAUGE (ATG) ACCEPTANCE TEST PROCEDURE}

\subsection{INSTRUCTIONS}

\subsection{PURPOSE}

This procedure checks that the shipment of the gauge received at Hanford is completely functional and has received no shipping damage. This procedure does not certify the gauge operation; that is done by the manufacturer.

\subsection{SCOPE}

This procedure provides acceptance testing for Enraf Series 854 level gauges used to monitor levels and/or waste densities in Hanford Waste Storage Tanks. The test will verify that the gauge functions according to the manufacturer's instructions and specifications and is properly setup prior to being delivered to the tank farm area. This ATP does not set up the gauge for any specific tank, but is generalized to permit tesing the gauge in prior to installation package preparation.

\subsection{REFERENCES}

- Instruction Manual Series 854 ATG Level Gauge, Enraf Inc., Part No. 4416.220, Version 2.2 (See CV-31560, vendor information file).

\subsection{RESPONSIBILITIES}

1.4.1 The Person In Charge (PIC) is responsible for coordinating the level gauge testing.

1.4.2 Maintenance (Instrument Craft) is responsible for performing the testing and recording the test results.

1.4.3 Quality Control is responsible for witnessing the tests, signing the data sheets when testing is completed and placing a "green tag" on the gauge after successful completion of the test. 


\subsection{DESCRIPTION OF THE SYSTEM}

Enraf-Nonius Series 854 level gauges are certified by Factory Mutual (FM) for National Fire Protectional Association (NFPA 70) hazardous Class I, Division I, Groups B, C, and D Locations. Its level measuring principle is based on the detection of variations in the weight of a displacer suspended in the process fluid. The displacer is connected to a wire wound on a precision measuring drum. A level change causes a change in the weight of the displacer which will be detected by the force transducer. Electronics within the gauge cause a servo motor to adjust the position of the displacer and compute the tank level based on the new position of the displacer drum. The gauge displays the level in decimal inches. An analog output signal transmits the level data for remote data processing. In densitometer mode, the principle of operation is similar. The gauge measures the weight of the displacer at various levels within the product and compares the measured weight with the known clean weight. The electronics then use this weight difference along with the known displacer volume and area to calculate product density. It should be noted that the only difference between the level measurement gauge and density measurement gauge is the installation of an EPROM (Eraseable, Programable, Read Only Memory) chip installed in the latter.

\subsection{TEST CONDITIONS AND EQUIPMENT REQUIRED}

The equipment listed below is required to perform this procedure.

- Portable Enraf Terminal (PET) Model No. 847

- Enraf Test Weights (Enraf PN 1854-061)

- Reamer (Enraf PN 4563.030) or \#31 dri11

- Enraf Extraction Tool (optional) 
WHC-SD-WM-ATP-077

REV 5

\subsection{TEST EXECUTION SECTION}

\section{NOTE:}

The commands typed on the PET or computer are shown in square brackets "[]" (The square brackets are NOT to be typed as part of the command). Included is any additional information the command requires. After typing the text within the square brackets, press the ENTER key. If an error is made during the typing of the command, use the backspace (BS) key to delete the error.

After entering a command, the PET or computer will give one of two responses: The first response will show the entered command with an "\&" character at the end (i.e. "TG\&"). This response tells the user that the gauge accepted the command. The second response will show the two digit command (i.e. TG) followed by a "!" and a three digit error code (i.e. "TG!053"). This command tells the user that the gauge did not accept the command. For a 1 ist of error codes, see the Enraf 854 ATG Level Gauge Instruction Manual, section 12.4 .

\section{PROCEDURE NOTE}

In the following steps, if values are requested, the values shall be recorded in the Test Execution Data Sheet (located at the end of this procedure) for the appropriate step number in the Value column. If verification is requested, write accept in the accept/reject column in the Test Execution Data Sheet for the appropriate step number.

If an error occurs in any step, an exception will be entered in the Exceptions Data Sheet 1 isting the step where the error occurred, and a general description of the error. Corrective actions shall be in accordance with section 3.0. A force transducer calibration may be performed at any time at the Test Conductor's discretion. 
WHC-SD-WM-ATP-077

REV 5

\subsection{INITIALIZING THE GAUGE}

\section{INFORMATION}

This section prepares the gauge for testing. It connects power and unlocks the servo motor.

2.1.1 Mount the gauge per the 854 ATG Level gauge Instruction Manual. Provide electrical connections to the gauge per the 854 ATG Level Gauge Instruction Manual, the National Fire Protection Association (NFPA 70) National Electrical Code.

2.1.2 Install the drum and displacer per the Enraf Series 854 ATG Leve1 Gauge Instruction Manual, Section 8.4.

2.1.3 Unlock the servo motor prior to connecting power per the 854 ATG Leve 1 Gauge Instruction Manual, Section 8.5 .

2.1.4 Connect the PET to the optical port located on the side of the gauge housing-op connect a computer to the gauge using the RS $232 \mathrm{C}$ pigtail, PET and bi-phase-mark-connector (see appendix A for guidance).

2.1.5 Connect the gauge to a $120 \mathrm{Vac}(+/-5 \mathrm{Vac})$ power source, per the 854 ATG Level Gauge Instruction Manual, Section 4.3.1. The display screen on the gauge will show one dark line. After approximately 20 seconds, the display will show the gauge initializing.

2.1.6 Configure the gauge per Appendix A. If the gauge is not setup to measure- level in inches, peconfigure the gatuge per appendi* $A$ (changing level dimensions).

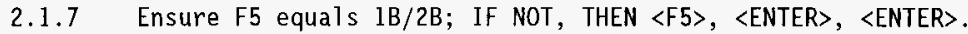

\subsection{CHECKING FOR ERROR CODES}

\section{INFORMATION}

Record any errors on the data sheet. Correct the errors, or enter it as an exception. For a list of error codes, see the Enraf 854 ATG Level Gauge Instruction Manual. 
2.2.1 Enter Command [EP] = "XPU error code". Verify that EP000 is displayed. Record verification in the data sheet.

2.2.2 Enter Command [ES] = "SPU error code". Verify that ES0000 is displayed. Record verification in the data sheet.

\subsection{TESTING THE LEVEL GAUGE OPERABILITY}

\section{INFORMATION}

This section enters data into the memory of the level gauge. These values tailor the gauge for the specific tank.

2.3.1 Enter Command [UN]. This command unlocks the gauge and allows the displacer to move downward to the floor or other hard surface.

\section{NOTE:}

If the displacer does not move downward, check to make sure that the drum moves freely on the bearings. If the drum does not move freely, perform the drum bearing removal/reconditioning procedure

in Appendix B. If the drum does move freely, re-calibrate the force transducer using the procedure in Appendix C. After drum bearing reconditioning or force transducer re-calibration, perform step 2.3.1 again. Document the drum bearing reconditioning or force transducer re-calibration as an exception.

2.3.2 Enter Command [W2=ENRAF2]. This command enters protection level 2.

2.3.3 Enter the following parameters into the gauge (Verify proper parameter entry and record the verification in the Data Sheet):

- $[\mathrm{TT}=+00900.00]$

("TANK TOP" parameter)

- [UR=+00900.00] ("UPPER REFERENCE" parameter)

- $[M H=+00890.00]$ ("MOTOR HIGH" parameter)

- $[M Z=+00880.00]$ ("LOCK TEST LIMIT" parameter)

- $[H H=+00870.00]$ ("HIGH HIGH ALARM" parameter) 
- $[H A=+00860.00]$

- $[L A=+00006.00]$

- $[\mathrm{LL}=+00003.00]$

- $[\mathrm{ML}=+00001.00]$

- $[R L=+00850.00]$
("HIGH ALARM" parameter)

("LOW ALARM" parameter)

("LOW LOW ALARM" parameter)

("MOTOR LIMIT SWITCH LOW" parameter)

("REFERENCE LEVEL" parameter)

2.3.4 Enter command $[A R]$. This command directs the gauge to accept the current value for "RL".

2.3.5 Enter command [EX].

NOTE:

Prior to executing step 2.3.6, verify that the opening to the gauge flange is blocked so that the displacer cannot be raised up into the drum housing.

2.3.6 Enter Command [CA]. This command raises the displacer. Verify that the displacer raises up to the gauge flange and stops. Record the verification in the data sheet.

2.3.7 Enter Command [UN].

2.3.8 After the gauge stabilizes, verify that the level reading in the gauge LCD display is reading within 0.10 inches of the RL value programmed in step 2.3.3. Record the verification in the data sheet.

2.3.9 Enter command [TG]. This commands tests the gauge.

2.3.10 Verify that the displacer rises a couple of inches and then goes back down to the RL. Record the verification in the data sheet.

\subsection{DRUM CIRCUMFERENCE VERIFICATION}

2.4.1 Enter Command [DC]. This command displays the preprogrammed drum circumference.

2.4.2 Verify that the drum circumference value displayed (DC) is the same as the value for the Drum circumference found engraved on the wire drum. Record the value in the data sheet. If the Drum Circumference value engraved on the wire drum does not exactly match the preprogrammed Drum Circumference (DC) value, 
perform steps 2.4.3 through 2.4.5, otherwise go to step 2.5. Note that display on computer is in meters, and engraved value is in millimeters.

\section{NOTE:}

This value is displayed in scientific notation.

The value will look like "DC=+.33000000E+00".

\subsubsection{Enter Command [W2=ENRAF2].}

2.4.4 Enter Command $[D C=+. X X X X X X X X E+00]$. The value for $X X X X X X X X X$ is the Drum Circumference value engraved on the wire drum. Record the value in the data sheet.

\subsubsection{Enter command [EX].}

\subsection{DISPLACER WEIGHT VERIFICATION}

2.5.1 Enter command [CA].

2.5.2 After the displacer rises a few inches, enter command [FR]. This command stops the displacer.

2.5.3 Enter command [MF]. This command measures the motor frequency.

2.5.4 After "FR" appears in the gauge's LCD display, PET display or computer display, enter command [WQ]. This command measures the weight of the displacer. Record the WQ value in the data sheet.

\section{NOTE:}

This value is displayed in scientific notation.

The value will look like "WQ=+.22300000E+03".

2.5.5 Verify that the WQ value is within 3 grams of the weight engraved on the displacer. Record the verification in the data sheet. 
2.5.6 If the value for $W Q$ is not within 3 grams $(.00300000 E+03)$ of the weight engraved on the displacer, calibrate the force transducer per the force transducer calibration procedure found in Appendix $C$. Document this calibration as an exception. After force transducer calibration, perform steps 2.5.3-2.5.5 again.

\section{NOTE:}

The previous step is not required for densitometer testing. A force transducer calibration is routinely performed for densitometers in the following sections. 
WHC-SD-WM-ATP- 077

REV 5

\subsection{TESTING THE DISPLAY (Densitometers Only)}

\section{INFORMATION}

This section tests for proper communications and the ability of the gauge to change from the Level Display to the Analog Display. The Analog Display wi11 only be used for diagnostics during gauge operation. The Level Display will be used during normal operation.

Enter these commands from the computer terminal.

2.6.1 Select item 2) SEND ITEMS from the LOGv18 menu.

2.6.2 Press F2, enter 00, and press ENTER to address the gauge ( $T A=00$ ). The transmission address of the gauge is displayed in the second column at the bottom of the screen.

2.6.3 Enter command [W1=ENRAF1] to enter protection level 1.

2.6.4 Enter command $[\mathrm{DF}=\mathrm{J}]$ to enter the analog display format $\mathrm{J}$.

2.6.5 Enter command [EX] to exit protection level 1, store the changed data and initialize the 854 ATG.

2.6.6 RECORD VERIFICATION that the analog display (format $J$ ) screen is displayed on the gauge after initialization. See Figure 7.9 (page $29)$ in the 854 ATG Instruction Manua?.

NOTE: The terminal display will not show the format change until the F2 key is pressed and then the ENTER key.

2.6.7 Enter command [W1=ENRAF1] to enter protection level 1.

2.6.8 Enter command $[\mathrm{DF}=\mathrm{B}]$ to enter the display format $\mathrm{B}$.

2.6.9 Enter command [EX] to exit protection level 1. store the changed data and initialize the 854 ATG. 
2.6.10 RECORD VERIFICATION that the level display (format B) screen is displayed on the gauge after initialization (See Figure 7.3. page 26 , in the 854 ATG Instruction manual).

\subsection{DENSITY CALIBRATION SETUP (Densitometers Only)}

\section{INFORMATION}

The drum circumference value, provided by the manufacturer, is used in calibrating the gauge for changes in level. The value insures the gauge reports level changes accurately.

2.7.1 Enter command [W2=ENRAF2] to enter protection level 2.

2.7.2 Enter command [SM] to enter the maintenance mode.

2.7.3 Enter command [GU] to raise the displacer and enter command [FR] to stop the displacer. Raise the displacer until it is in fuTl view, and can be easily accessed. RECORD the level value.

CAUTION: When entering the [FR] command, be aware of the time delay between entering the command and the displacer stopping.

2.7.4 Enter command [SO] to exit the maintenance mode.

2.7.5 Enter command $[M Z=+x x x x x . x x]$ to enter the level value recorded in 2.7.3 as the Lock Test motor limit setting. RECORD VERIFICATION of proper value entry. The gauge will automatically return to this level during a LT (lock test) command.

2.7.6 Enter command [WT=EDD] to disable the wire-rupture detection. RECORD VERIFICÁTION of proper value entry. The disabling allows for calibration.

2.7.7 Enter command [EX] to exit protection level 2. store al1 entered data and initialize the 854 ATG.

\subsection{DENSITY CALIBRATION (Densitometers Only)}


WHC-SD-WM-ATP-077

REV 5

\section{INFORMATION}

Density calibration requires the gauge to be fully operational. When exchanging items hanging on the wire, make sure the gauge is de-energized to avoid damage to the force transducer. Be sure to maintain some tension on the wire while changing weights to prevent the wire from uncoiling from the drum.

No liquid is required for this calibration.

2.8.1 Replace the displacer with the $25 \mathrm{~g}$ test weight on the measuring wire.

CAUTION: When exchanging items hanging on the wire, make sure the gauge is de-energized to avoid damage to the force transducer. Also be sure to maintain tension on the wire to avoid unraveling the wire from the drum.

2.8.2 Enter command [UN] to release the test weight.

2.8.3 Enter command [BT] to begin a balance test. The ATG will now find the average frequency corresponding to the $25 \mathrm{~g}$ weight. Wait until the test has been completed.

2.8.4 Enter command $[\mathrm{BF}]$ to request the measured average frequency after completion of the balance test. RECORD the frequency. Do not yet reprogram this value in the gauge. Reprogramming must be done after completion of all four calibration measurements.

2.8.5 Enter command [UN] to release the test weight.

2.8.6 Enter command [LT] to raise the test weight to the MZ level.

2.8.7 Add the $75 \mathrm{~g}$ weight to the $25 \mathrm{~g}$ weight.

2.8.8 Enter command [UN] to release the test weight.

2.8.9 Enter command $[\mathrm{BT}]$ to begin a balance test. The ATG will now find the average frequency corresponding to the $25 \mathrm{~g}+75 \mathrm{~g}$ weight combination. Wait until the test has been completed.

2.8.10 Enter command $[\mathrm{BF}]$ to request the measured average frequency after completion of the balance test. RECORD the frequency. 
2.8.11 Enter command [UN] to release the test weight.

2.8.12 Enter command [LT] to raise the test weight again.

2.8.13 Replace the $75 \mathrm{~g}$ weight with the $150 \mathrm{~g}$.

2.8.14 Enter command [UN] to release the test weight.

2.8.15 Enter command [BT] to begin a balance test. The ATG will now find the average frequency corresponding to the $25 \mathrm{~g}+150 \mathrm{~g}$ test-weight combination. Wait until the test has been completed

2.8.16 Enter command [BF] to request the measured average frequency after completion of the balance test. RECORD the frequency.

2.8.17 Enter command [UN] to release the test weight.

2.8.18 Enter command [LT] to raise the test weight again.

2.8.19 Replace the $150 \mathrm{~g}$ weight with the $225 \mathrm{~g}$ weight.

2.8.20 Enter command [UN] to release the test weight.

2.8.21 Enter command [BT] to begin a balance test. The ATG will now find the average frequency corresponding to the $25 \mathrm{~g}+225 \mathrm{~g}$ test-weight combination. Wait until the test has been completed.

2.8.22 Enter command $[\mathrm{BF}]$ to request the measured average frequency after completion of the balance test. RECORD the frequency.

2.8.23 Enter command [UN] to release the test weight.

2.8.24 Enter command [LT] to raise the test weight again.

2.8.25 Enter command [W2=ENRAF2] to enter protection level 2.

2.8.26 Enter command $[F 0=+. x x x x x x \times x E+x x]$ to input the frequency value recorded in Step 2.8.4. RECORD VERIFICATION of proper value entry.

2.8.27 Enter command $[F 1=+. x x x \times x x x \times E+x x]$ to input the frequency value recorded in Step 2.8.10. RECORD VERIFICATION of proper value entry.

2.8.28 Enter command $[F 2=+. x x x x x x x x E+x x]$ to input the frequency value recorded in Step 2.8.16. RECORD VERIFICATION of proper value entry.

2.8.29 Enter command $[F 3=+. x x x x x x \times x E+x x]$ to input the frequency value recorded in Step 2.8.22. RECORD VERIFICATION of proper value entry. 
2.8.30 Enter command $[D W=+. x x x x x x x x E+x x]$ to assign the value for $D W$, which is engraved on the density displacer. RECORD VERIFICATION of proper value entry.

2.8.31 Enter command $[D V=+. x x x x x x x x E+x x]$ to assign the value for $D V$, which is engraved on the density displacer and recorded in Step MMM?. RECORD VERIFICATION of proper value entry.

2.8.32 Enter command [DA=+.16000000E+02] to assign the value for the displacer area. RECORD VERIFICATION of proper value entry.

2.8.33 Enter command [S1=+.24500000E+03] to assign the value for the weight of the displacer with one-third submerged. This value is used to determine when Il has been reached. RECORD VERIFICATION of proper value entry.

2.8.34 Enter command [WT=EDE] to enable the wire rupture detection. RECORD VERIFICATION of proper value entry.

2.8.35 Enter command $[\mathrm{RM}=+.24500000 E+03]$ to assign the value for wire tension during execution of the AR command. RECORD VERIFICATION of proper value entry.

2.8.36 Enter command [EX] to exit protection level 2 .

2.8.37 Replace the test weights with the displacer on the measuring wire.

CAUTION: When exchanging items hanging on the wire, make sure the gauge is de-energized to avoid damage to the force transducer. Also be sure to maintain tension on the wire to avoid unraveling the wire from the drum. 
WHC-SD-WM-ATP-077

REV 5

\subsection{TRANSPORTING THE LEVEL GAUGE}

\section{CAUTION}

This section prepares the gauge for transport. The motor must be locked to prevent possibie damage to the force transducer.

2.9.1 If the level gauge display is not in FORMAT B (see the 854 ATG Level Gauge Instruction Manual, Figure 7.3), enter command [W]=ENRAF1]. Once in Protection Leve1 1, enter command [DF=B] (this command switches the gauge to display format B). Enter command $[\mathrm{EX}]$.

2.9.2 If using a computer for the testing, $\log$ the gauge data onto the computer (see Appendix A).

2.9.3 Disconnect the gauge from the power source.

2.9.4 "Lock" the servo motor, per the 854 ATG Level Gauge Instruction Manual, Section 8.5 , prior to transporting the gauge.

2.9.5 Remove the drum and displacer, per the 854 ATG Level Gauge Instruction Manual, Section 8.4, prior to transporting the gauge.

\subsection{DATA}

2.10.1 Mail a copy of the completed data sheets, vender information, and hardcopy of the logfile to J. H. Huber at T4-07. 
WHC-SD-WM-ATP-077

REV 5

\subsection{EXCEPTIONS TO ACCEPTANCE TEST}

Exceptions to the test are dispositioned and agreed to by all witnesses. Actions taken regarding disposition are noted on the "Exception to Acceptance Test" sheet. Typical dispositions are:

- Test approved with exception (i.e., rerun of the acceptance test unnecessary).

- Entire acceptance test to be repeated after the discrepancy has been corrected.

- ATP step(s) affected to be repeated after the discrepancy has been corrected.

\subsection{TEST DATA MANAGEMENT}

The test data shall be entered on the attached data sheets. Witness signatures at the bottom of the data sheet indicates that the witness agrees to the accuracy of the data recorded and comparisons made.

Upon successful completion of testing activities, the master copy of the DATA SHEETS will be signed by the Test Witnesses. An appropriate "Acceptance Test Report" sha11 be generated to publish the results of testing activities.

\subsection{ACCEPTANCE TEST REPORT GUIDANCE}

The data sheets which are completed during the testing activities will be included in the Acceptance Test Report. If additional gauges are tested using this procedure, a different data sheet will be used for each gauge and added to the ATR as a revision. 


\begin{tabular}{|l|l|l|l|l||}
\hline \multicolumn{3}{|c|}{ TEST EXECUTION DATA SHEET } \\
\hline Date: & \multicolumn{1}{|l|}{ Value } & Comment \\
\hline Gauge Serial Number: & Densitometer? Yes No \\
\hline \multicolumn{2}{|l|}{ Test Performed By: } & Vamber: \\
\hline $\begin{array}{l}\text { Reference } \\
\text { Sequence }\end{array}$ & Attribute & $\begin{array}{c}\text { Accept/ } \\
\text { Reject }\end{array}$ & & \\
\hline 2.2 .1 & EP & & & \\
\hline 2.2 .2 & ES & & & \\
\hline 2.3 .3 & PARAMETERS & & & \\
\hline 2.3 .6 & CA & & & \\
\hline 2.3 .8 & RL & & & \\
\hline 2.3 .10 & RL & & & \\
\hline 2.4 .2 & DC & & & \\
\hline 2.4 .4 & DC & & & \\
\hline 2.5 .4 & WQ & & & \\
\hline 2.5 .5 & WQ & & & \\
\hline 2.6 .6 & J & & & \\
\hline 2.6 .10 & B & & & \\
\hline 2.7 .3 & MZ & & & \\
\hline 2.7 .5 & MZ & & & \\
\hline 2.7 .6 & EDD & & & \\
\hline
\end{tabular}


WHC-SD-WM-ATP-077

REV 5

\section{TEST EXECUTION DATA SHEET CONTINUED}

\begin{tabular}{|l|l|l|l|l||}
\hline \multicolumn{3}{|c||}{ TEST EXECUTION DATA SHEET } \\
\hline 5.2 .8 .4 & F0 & & & \\
\hline 2.8 .10 & F1 & & & \\
\hline 2.8 .16 & F2 & & & \\
\hline 2.8 .22 & F3 & & & \\
\hline 2.8 .26 & F0 & & & \\
\hline 2.8 .27 & F1 & & & \\
\hline 2.8 .28 & F2 & & & \\
\hline 2.8 .29 & F3 & & & \\
\hline 2.8 .30 & DW & & & \\
\hline 2.8 .31 & DV & & & \\
\hline 2.8 .32 & DA & & & \\
\hline 2.8 .34 & EDE & & & \\
\hline 2.8 .35 & RM & & & \\
\hline 2.9 .4 & MOTOR LOCK & & & \\
\hline
\end{tabular}

Test Witnesses:

$\begin{array}{ll}\text { PIC } & \text { Date } \\ \text { QuaTity Control } & \text { Date } \\ \text { Maintenance } & \text { Date }\end{array}$


WHC-SD-WM-ATP-077

REV 5

EXCEPTIONS DATA SHEET

Gauge Serial Number:

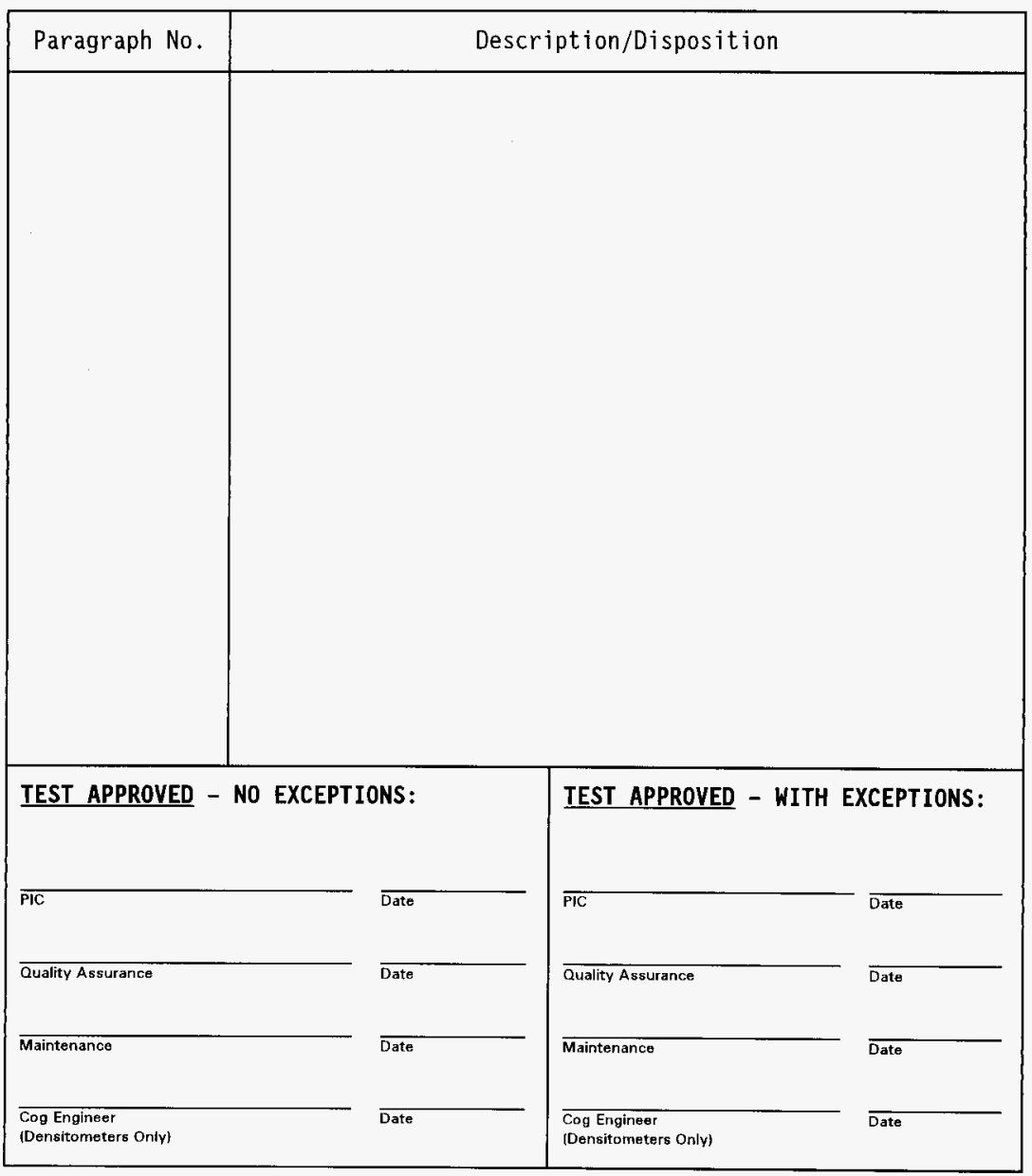




\title{
WHC-SD-WM-ATP-077 \\ REV 5
}

\section{ENRAF SERIES 854 ADVANCED TECHNOLOGY GAUGE (ATG) \\ ACCEPTANCE TEST PROCEDURE}

\author{
APPENDIX A
}

COMPUTER SETUP GUIDANCE:

I 1. Turn PET ON. Connect the-infrared connector from the PET to the ENRAF gauge.

2. Enter the TA command, note the gauge address displayed in the PET display, (i.e. TA05). TURN PET OFF.

3. Disconnect the infrared connector, and connect the computer and PET to the gauge per Figure A-1. Power up PET/gauge as required.

4. Place the PET in SETUP MODE by pressing keys control-esc at the same time.

5. Press the down arrow $(\downarrow)$ on the PET keyboard until MODE is displayed at the top of the PET display.

6. Press the right arrow $\rightarrow$ until the cursor is underneath RS232.

7. Press the down arrow $(\downarrow)$ until the display on the PET reads "RS-232 Baudrate".

8. Verify (and if necessary correct) the cursor is underneath 1200 .

9. Press the down arrow unti1 the PET display reads SETUP MODE, and then press, controlesc at the same time.

10. Turn on the computer, respond no to accessing network resources, push any key to continue.

11. At the $c: \backslash>$ prompt on the computer display, access the logger directory by typing, cd) logger

12. Start the logger program by typing, LOGV18

13. Use the computer arrow keys and highlight item \#1, "Setup system", then press the enter key. 
WHC-SD-WM-ATP-077

REV 5

\section{ENRAF SERIES 854 ADVANCED TECHNOLOGY GAUGE (ATG) ACCEPTANCE TEST PROCEDURE}

14. Highlight item \#4, "Gauge address" and press enter.

15. Enter the gauge address noted from step \#2 (note the flashing cursor), then press enter.

16. Verify that the other parameters shown in the "SETUP MENU" display match the parameters shown below. If the parameters don't match, change them using the procedure in steps 14 and 15 .

\section{SETUP MENU}

1) RS232C port \& Baudrate

2 ) Add header to every file

3 ) Ciu address

*4 ) Gauge Address

5) Max. number of records in file LOGV17.CYC

6) Name cyclusfile

7 ) Max. number of retries per CIU request

8) Timeout $\mathrm{CIU}$

9) Turn around delay

A ) ITEM directory

B ) $C Y C$ file directory

C) $L O G^{-}$file directory

D) file to field file directory

E Library directory

F.) RAM disk

G ) Return to main menu

(port 101200 Baud.)

(N)

()

$(\mathrm{XX})$

(100)

(LOGV17.CYC)

(3)

(9 sec.)

(0 sec.)

(C. \LOGGER ITEMS )

(C) LOGGER CYC )

(C: \LOGGER \LOG\)

(C: \LOGGER /FTFY)

(C: $\backslash$ LOGGER $\backslash L I B \backslash)$

(1)

$\star X X$ is obtained from gauge parameter [TA]

17. Hightight item $\# G$, "Return to main menu", press enter key.

18. A prompt will ask, "Save new setup on disk $(y, n)$ ?, type, y for a yes response.

19. Highlight item \#2, "Send items", press enter key.

20. Return to section 2.1.7.

CHANGING LEVEL DIMENSIONS:

1. 〈ESC $>$ from LOGGER'S "MAIN MENU", enter the "SPECIAL MENU". 


\section{ENRAF SERIES 854 ADVANCED TECHNOLOGY GAUGE (ATG)} ACCEPTANCE TEST PROCEDURE

2. Enter the "CHANGE DIMENSIONS" menu.

3. Enter the gauge's "TRANSMISSION ADDRESS" (TA).

4. Enter "1) LEVEL DIMENSION ( $X X X X X X X)$ "

5. Enter "TO INCHES"

6. Return to the "MAIN MENU"

7. Return to "SEND ITEMS"

LOGGING GAUGE DATA ONTO COMPUTER:

1. From LOGGER'S "MAIN MENU", enter the "SPECIAL MENU".

2. Enter "I) GAUGE LOGGING TO DISK".

3. Enter the gauge's "TRANSMISSION ADDRESS" (TA). 


\section{WHC-SD-WM-ATP-077 \\ REV 5}

ENRAF SERIES 854 ADVANCED TECHNOLOGY GAUGE (ATG) ACCEPTANCE TEST PROCEDURE

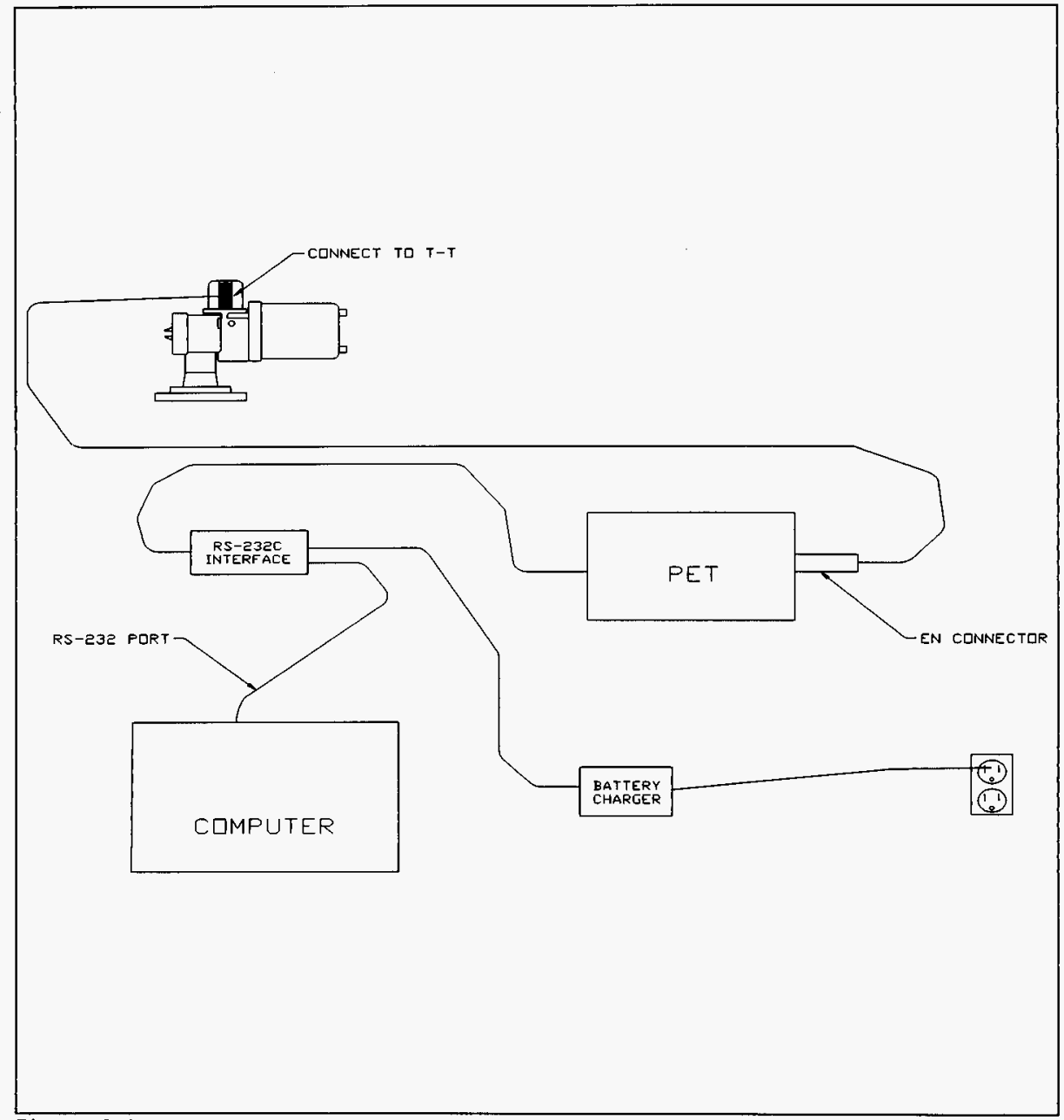

Figure A-1 


\section{WHC-SD-WM-ATP-077 \\ REV 5 \\ ENRAF SERIES 854 ADVANCED TECHNOLOGY GAUGE (ATG) \\ ACCEPTANCE TEST PROCEDURE}

APPENDIX B

DRUM BEARING REMOVAL/RECONDITIONING

1. Disconnect the gauge from the power source. Use a PLD to 1ock out power.

2. "Lock" the servo motor, per the 854 ATG Level Gauge Instruction Manual, Section 8.5.

3. Remove the drum and displacer per the 854 ATG Level Gauge Instruction Manual, Section 8.4.

4. Remove the drum shaft bushing from the gauge per the 854 ATG Level Gauge Instruction Manua1, Figure 9.3.

5. Remove the bearings (2 black disks on each end of the bushing) from the drum shaft bushing per the 854 ATG Level Gauge Instruction Manual, Figure 9.3.

6. Use the reamer or the \#31 drill to ream out both bearings.

7. Reinstall the reconditioned drum bearings into the drum shaft bushing.

8. Reinstall the drum shaft busing into the gauge.

9. Reinstall the drum and displacer, per the 854 ATG Level Gauge Instruction Manual, Section 8.4.

10. "Unlock" the servo motor, per the 854 ATG Level Gauge Instruction Manual, Section 8.5 .

11. Connect the gauge to the power source. 


\title{
WHC-SD-WM-ATP-077 \\ REV 5 \\ ENRAF SERIES 854 ADVANCED TECHNOLOGY GAUGE (ATG) \\ ACCEPTANCE TEST PROCEDURE
}

\author{
APPENDIX C
}

\section{FORCE TRANSDUCER CALIBRATION}

1. Raise the displacer to approximately 6" below the gauge flange by entering command $[\mathrm{CA}]$. To stop the displacer, enter command [FR].

2. Enter command [W2=ENRAF2].

3. Enter command $[W T=D D D]$. This command disables the "wire-rupture" protection.

4. Remove the displacer from the measuring wire.

5. Attached the 25 gram weight to the measuring wire loop. The 25 gram weight is the smallest of weights in the set and has two hooks.

6. Enter command [BT]. This command activates a BALANCE TEST. The BALANCE TEST wi\}1 take approximately five minutes to complete.

7. After "FR" appears in the gauge's LCD display, PET display or computer display, enter command $[\mathrm{BF}]$. This command will display the frequency measured during the BALANCE TEST. Record this frequency (FO) below:

$\mathrm{FO}=$

8. Attach the 75 gram weight to the 25 gram weight. The 75 gram weight is the third smallest in the set. Note: If there is insufficient room for the test weights to move downward (approximately 12"), perform step 1 to raise the test weights.

9. Repeat steps 6 and 7. Record the frequency (F1) below:

$\mathrm{Fl}=$

10. Remove the $75 \mathrm{gram}$ weight and attach the $150 \mathrm{gram}$ weight to the 25 gram weight. The 150 gram weight is the second largest weight in the set. Note: If there is insufficient room for the test weights to move downward (approximately 12 "), perform step 1 to raise the test weights.

11. Repeat steps 6 and 7. Record the frequency (F2) below:

$\mathrm{F} 2=$

12. Remove the 150 gram weight and attach the 225 gram weight to the 25 gram weight. The 225 gram weight is the largest weight in the set. Note: If there is 


\section{WHC-SD-WM-ATP-077 \\ REV 5}

\section{ENRAF SERIES 854 ADVANCED TECHNOLOGY GAUGE (ATG) ACCEPTANCE TEST PROCEDURE}

insufficient room for the test weights to move downward (approximately $12^{\prime \prime}$ ), perform step 1 to raise the test weights.

13. Repeat steps 6 and 7. Record the frequency (F3) below:

$\mathrm{F} 3=$

14. Enter command [W2=ENRAF2].

15. Enter command $[F 0=+. X X X X X X X X E+X X]$. This command re-programs frequency 0 . The value of $F 0$ is the value obtained in step 7 .

16. Repeat step 15 for frequencies F1, F2 and F3. The values for F1, F2 and F3 are the values obtained in steps 9,11 and 13 respectively.

17. Enter command $[W T=E D E]$. This command enables the "wire-rupture" protection.

18. Enter command [EX].

19. Remove weights and install displacer.

20. Return to section 2.6. 